\title{
Relationship between clinical performance and professional self-concept in critical care nurses
}

Narges Eskandaria, Mohammad Abbasia,*, Mohammad Abbasiniaa, Reza Norouzadeh ${ }^{\mathrm{b}}$

aSpiritual Health Research Centre, Qom University of Medical Sciences and Health Services, Qom, Qom 37185, Iran

${ }^{b}$ Nursing and Midwifery Faculty, Shahed University, Tehran, Tehran 4419118651, Iran

Received: 13 March 2021; Accepted: 28 April 2021; Published: 20 December 2021

Abstract: Objective: To determine the relationship between clinical performance and professional self-concept in critical care nurses. Methods: This study was conducted on 308 critical care nurses. Data gathering instruments were nurses' clinical performance questionnaire (NCPQ) and nursing professional self-concept measure (NPSCM). Independent sample $t$-test, one-way analysis of variance (ANOVA), and Pearson correlation coefficient were used for data analyses.

Results: The average age of the nurses was $33.74 \pm 7.01$ years. The clinical performance score of female nurses was significantly higher than male nurses. In the domain of clinical performance, clinical judgment and clinical inquiry had the highest and lowest scores, respectively. In the nurses' professional self-concept, the highest and lowest scores were awarded to the subscales of selfconfidence and staff relations, respectively. In addition, there was a significant positive correlation between self-concept and clinical performance of nurses.

Conclusions: Increasing professional self-concept improves the clinical performance of critical care nurses. Professional self-concept enhancement measures are recommended to improve the clinical performance of nurses in critical care units.

Keywords: clinical performance $\bullet$ critical care unit • nurses $\bullet$ self-concept

(C) Shanxi Medical Periodical Press.

\section{Introduction}

Among health-care providers, nurses spend more time caring for patients..$^{1,2}$ Providing good quality nursing services in all health-care systems is a concern. ${ }^{3}$ As intensive care units (ICU) are equipped with new technologies, there is a general expectation from nurses that they have the skills to provide quality care. ${ }^{3,4}$ Quality health care is defined as "acceptable levels of health services", which are in line with up-to-date knowledge, leading to favorable health outcomes. ${ }^{5}$ Given that providing quality services is the key to the success of health organizations, in the health system, the performance of nurses is an important guarantor for the desired health outcome. In this regard, Kahya and Oral (2018) suggest that frequent evaluation of nurses' performance ensures the optimal care and clinical outcome in the patient. ${ }^{6}$ Usually, the quality of nursing care

How to cite this article: Eskandari N, Abbasi M, Abbasinia M, Norouzadeh R. Relationship between clinical performance and professional self-concept in critical care nurses. Front Nurs. 2021;4:437-444.

\footnotetext{
* Corresponding author.

E-mail: dr.mabbasi@muq.ac.ir; Mohamad_abbasi55@yahoo.com (M. Abbasi)..
} 
is evaluated in terms of the strengths and weaknesses of clinical practice to continuously improve nurses' performance. ${ }^{7}$ Nurses' performance appraisal can help to understand the current situation and its compliance with clinical standards, ${ }^{6}$ improve professional skills, ${ }^{8}$ strengthen relationships, identify educational needs, ${ }^{9}$ reinforce positive behaviors, and improve the working environment. ${ }^{10}$ Today, improving the quality of care has received serious attention as one of the important indicators of health system accreditation. ${ }^{11}$ Several studies have been conducted on the quality of nursing care in Iran. Some studies focus on the relatively high prevalence of nursing medication errors. ${ }^{7,12}$ For example, a study shows that nurses' performance in endotracheal tube suctioning and artificial airway removal is lower than expected..$^{13}$ Some studies have shown that nurses' performance in areas of cooperation and support is better than clinical assessment and conflict management. ${ }^{4,10}$ Professional self-concept is one of the factors influencing nurses' competencies to provide care. ${ }^{14}$ The professional self-concept involves nurses' information and beliefs about their own roles, values, and behaviors. ${ }^{15}$ Therefore, professional self-concept is a necessity for nurses to perform proper clinical care.$^{16}$ It has been found that nurses with high professional selfconcept have more respect for the patient and more responsibility in performing clinical activities. ${ }^{15,17,18} \mathrm{Sev}$ eral studies have examined the relationship between nurses' performance and professional self-concept. Lee and Yang (2015) have concluded that the improvement of nurses' professional self-concept improves their clinical performance. ${ }^{19}$ Also, Badiyepeymaie Jahromi et al. (2015) reported a direct relationship between professional self-concept and nursing students' performance in planning, interpersonal relationship, and leadership. ${ }^{14}$ Considering the above, it can be seen that there is not much evidence regarding the relationship between the professional self-concept of intensive care nurses and their clinical performance. Studies conducted in Iran have focused on other topics, such as measuring the nurses' professional self-concept and its correlation with working stress. ${ }^{20,21}$ Also, a study in the selected university hospitals of Tehran reveals professional self-concept as the weakness in leadership among ICU nurses despite their relatively high scores in terms of knowledge dimension. ${ }^{22}$

The importance of addressing the issue of professional self-concept in nurses working in the ICU is due to the fact that these nurses always face a lot of stress in their workplace. At the same time, they must make decisions quickly without error in patients in critical conditions. Therefore, the authors became curious to examine the relationship between professional self-concept and the components of clinical performance of critical care nurses.

\section{Methods}

This descriptive correlational study was conducted in 2018 in ICU nurses working in intensive care settings (ICUs, CCU, dialysis, and emergency departments) of teaching hospitals of Medical Sciences, Qom, Iran. Three hundred and fifty nurses were involved in the study based on the reported standard deviation $(\mathrm{SD}=23.67)$ in the Golestan study ${ }^{23}$ with considering $\alpha=0.05, \beta=0.1$, and $d=4$. The inclusion criteria were a minimum of 6 months of work experience in the critical care unit, bachelor's degree in nursing, and willingness to participate in the study.

Data collecting instruments were a demographic data sheet, nurse's clinical performance questionnaire' (NCPQ), and nursing professional self-concept measure (NPSCM). The NCPQ includes 64 items on nurses' activities in eight subscales (i.e., clinical judgment, advocacy and moral agency, caring practices, facilitation of learning, collaboration, systems thinking, response to diversity, and clinical inquiry).,24 In Karimyar Jahromi (2013), the reliability of the Persian version of NCPQ has been confirmed $(R=0.83) .{ }^{4}$ To determine the score of the nurse's performance, the answer "yes" was given a score of "one" and "zero" for the response "no." The total performance score and its related domains were $0-100$. In this way, the score of each nurse is multiplied by the fraction (100 divided by the number of items). The level of performance was classified as 0-33 (poor), 34-66 (average), and 67-100 (good). The NPSCM was designed by Cowin (2001) to assess the nurses' professional self-concept. ${ }^{17}$ The questionnaire contains a total of 36 items that represent six subscales: (1) general self-concept, (2) nursing care, (3) staff relations, (4) communication, (5) knowledge, and (6) leadership. Each subscale consists of six items and all items are responded to on a six-point Likert scale ranging from 1 (complete disagree) to 6 (complete agree). The NPSCM makes a potential score range of $36-216 .{ }^{25}$ The validity of the Persian version of NPSCM was confirmed by Badiyepeymaie-Jahromi et al. (2014) and also its reliability was confirmed (Cronbach's alpha $=0.97) .{ }^{15}$

The data were analyzed by descriptive and analytic tests using SPSS software v. 22 (IBM Inc., Chicago, IL, USA). Based on the K-S test results, all variables had a normal distribution. Therefore, the independent-sample t-test and one-way analysis of variance (ANOVA) were used to compare the mean scores between the subgroups of the participants. Moreover, the Pearson correlation coefficient was calculated to examine the 
association between nurses' performance and professional self-concept scores. The level of significance was 0.05 .

This study was approved by the research ethics committee of Qom university of medical sciences (ethical approval code: IR.MUQ.REC.1396.85). All the participants were informed of the aim of the study. Verbal and written consents were obtained from all nurses. Identity protection, anonymity, voluntary participation, not being forced, and the right to withdraw from the study at any time were emphasized by the researcher. Participants were also assured that their information would remain confidential.

\section{Results}

Of the 350 questionnaires, 308 were suitable for analysis. The mean age of the participant nurses was $33.74 \pm 7.01$ years and 67 nurses $(21.9 \%)$ were female. A total of 229 nurses $(74.8 \%)$ were married. The mean work experience in the critical care unit was $6.71 \pm 5.55$ years. The clinical performance score in female nurses was significantly higher than in men $(P<0.030)$. As to the results of one-way ANOVA, there was a significant relationship between the professional self-concept with types of employment status $(P=0.005)$. Independent samples t-test showed a

\begin{tabular}{|c|c|c|c|}
\hline Variables & $\mathrm{N}(\%) /$ mean $(\mathrm{SD})$ & Professional self-concept & Clinical performance \\
\hline Age (year) & $33.74(7.01)$ & & \\
\hline$R$ & & 0.03 & 0.02 \\
\hline$P$-value* & & 0.52 & 0.69 \\
\hline \multicolumn{4}{|l|}{ Gender } \\
\hline Female & 239 (77.59) & $178.93(31.38)$ & $74.30(23.60)$ \\
\hline Male & $67(21.75)$ & $174.28(33.61)$ & $67.39(24.70)$ \\
\hline Missing & $2(0.64)$ & & \\
\hline P-value $\$$ & & 0.29 & 0.03 \\
\hline \multicolumn{4}{|l|}{ Marital status } \\
\hline Married & 229 (74.35) & $177.51(32.10)$ & $73.56(22.80)$ \\
\hline Single & $77(25)$ & $177.75(32.87)$ & $69.63(28.16)$ \\
\hline Missing & $2(0.64)$ & & \\
\hline$P$-value $\$$ & & 0.95 & 0.20 \\
\hline \multicolumn{4}{|l|}{ Academic educational level } \\
\hline Associate degree & $12(3.89)$ & $170.16(74.33)$ & $67.43(22.57)$ \\
\hline Bachelor degree & 277 (89.93) & $177.56(32.66)$ & $72.48(24.54)$ \\
\hline Master degree & $17(5.51)$ & $182.37(21.92)$ & $75.74(22.06)$ \\
\hline Missing & $2(0.64)$ & & \\
\hline P-value\# & & 0.66 & 0.61 \\
\hline \multicolumn{4}{|l|}{ Employment status } \\
\hline Permanent & $218(70.77)$ & $190.45(30.90)$ & 75.65 (27.46) \\
\hline Contractual & $45(14.61)$ & $167.15(34.72)$ & 72.09 (23.09) \\
\hline Temporary & $40(12.98)$ & $179.22(30.21)$ & 72.65 (23.73) \\
\hline Missing & $5(1.63)$ & & \\
\hline P-value\# & & 0.005 & 0.84 \\
\hline Overall work experience, year & $10.05(6.46)$ & & \\
\hline$R$ & & 0.05 & 0.003 \\
\hline$P$-value* & & 0.38 & 0.95 \\
\hline Work experience in the critical care unit & $6.71(5.55)$ & & \\
\hline$R$ & & 0.03 & 0.023 \\
\hline$P$-value* & & 0.38 & 0.95 \\
\hline
\end{tabular}

Note: *Regression; \# ANOVA; \$ t-test.

ANOVA, one-way analysis of variance; SD, standard deviation.

Table 1. Relationship between nurses' demographic characteristics with professional self-concept and clinical performance. 
significant relationship between clinical performance and gender $(P=0.030)$ (Table 1$)$. In clinical performance, nurses had the highest mean score in clinical judgment (80.74 \pm 21.64$)$ (Table 2). Moreover, in professional self-concept, nurses had the highest mean score in general self-concept $(36.60 \pm 5.69)$. Using Pearson's correlation coefficient, positive correlations were found

\begin{tabular}{lc}
\hline Variable & Mean \pm SD \\
\hline \hline Clinical performance & \\
Overall clinical performance & $72.54 \pm 24.29$ \\
Clinical judgment & $80.74 \pm 21.64$ \\
Advocacy and moral agency & $74.96 \pm 28.55$ \\
Caring practices & $75.47 \pm 28.48$ \\
Collaboration & $67.80 \pm 33.39$ \\
Systems thinking & $70.97 \pm 30.52$ \\
Response to diversity & $70.46 \pm 34.35$ \\
Clinical inquiry & $65.08 \pm 34.16$ \\
Facilitation of learning & $74.16 \pm 31.79$ \\
Professional self-concept & \\
Overall professional self-concept & $177.62 \pm 32.20$ \\
General self-concept (self-confidence) & $36.60 \pm 5.69$ \\
Caring & $30.54 \pm 5.66$ \\
Knowledge & $29.93 \pm 5.61$ \\
Staff relations & $27.79 \pm 6.48$ \\
Communication & $30.15 \pm 5.30$ \\
Leadership & $28.99 \pm 7.05$ \\
\hline
\end{tabular}

Note: SD, standard deviation.

Table 2. The mean and SD of critical care nurses' clinical performance, professional self-concept, and their subscales. between the nursing professional self-concept scores and clinical performance so that an increase in the professional self-concept was accompanied by an increase in the clinical performance (Table 3).

\section{Discussion}

In this study, the ability of intensive care nurses in clinical practice and their professional self-concept was studied. As seen in the results, nurses scored higher on the clinical judgment and lower on the clinical inquiry. Congruent with this finding, Karimyar Jahromi (2013) in evaluating the quality of performance of nurses in ICUs based on synergy model showed that nurses have been in good condition in terms of clinical judgment and the lowest performance was related to clinical research inquiry. ${ }^{4}$ Clinical judgment is an important skill for nurses and the basis of safe and quality nursing care. ${ }^{26}$ Clinical judgment is the inference that the nurse draws from the analysis of available information. ${ }^{27}$ Sophisticated care requirements in ICUs lead nurses to always face important clinical judgments. Accordingly, for intelligent clinical judgments, intensive care nurses must have sufficient and up-to-date professional knowledge for clinical reasoning based on critical thinking and problem-solving skills to prioritize care and interact appropriately with the patient and the treatment team. ${ }^{28,29}$ Nurses with such competencies are usually more self-expressive and make better clinical decisions in the patient care. ${ }^{30}$ Nurses in this study show low competencies in the clinical inquiry. Similar studies in Iran also indicate a low score of clinical inquiry in nurses..$^{4,10,31}$ The clinical inquiry as an ongoing process of questioning and

\begin{tabular}{|c|c|c|c|c|c|c|c|}
\hline \multirow[b]{2}{*}{ Clinical performance Variables } & \multicolumn{7}{|c|}{ Professional self-concept subscales } \\
\hline & $\begin{array}{c}\text { Self- } \\
\text { confidence }\end{array}$ & Caring & Knowledge & $\begin{array}{c}\text { Staff } \\
\text { relations }\end{array}$ & Communication & Leadership & $\begin{array}{c}\text { Overall professional } \\
\text { self-concept }\end{array}$ \\
\hline Clinical judgment & 0.286 & 0.240 & 0.295 & 0.214 & 0.277 & 0.259 & 0.296 \\
\hline Advocacy and moral agency & 0.332 & 0.339 & 0.378 & 0.303 & 0.344 & 0.314 & 0.377 \\
\hline Caring practices & 0.315 & 0.282 & 0.348 & 0.286 & 0.313 & 0.282 & 0.341 \\
\hline Collaboration & 0.313 & 0.262 & 0.315 & 0.274 & 0.299 & 0.241 & 0.317 \\
\hline Systems thinking & 0.292 & 0.286 & 0.293 & 0.270 & 0.325 & 0.247 & 0.316 \\
\hline Response to diversity & 0.305 & 0.292 & 0.332 & 0.278 & 0.314 & 0.268 & 0.333 \\
\hline Clinical inquiry & 0.336 & 0.287 & 0.324 & 0.316 & 0.336 & 0.276 & 0.347 \\
\hline Facilitation of learning & 0.218 & 0.179 & 0.209 & 0.169 & 0.234 & 0.137 & 0.212 \\
\hline Overall clinical performance & 0.363 & 0.314 & 0.361 & 0.322 & 0.367 & 0.306 & 0.380 \\
\hline
\end{tabular}

Note: *All correlation coefficients are significant at $P$-value $<0.001$

Table 3. Correlation between professional self-concept and clinical performance scores* 
evaluating practice through research and experiential learning ${ }^{32}$ can improve the quality of nursing care. However, several studies show the nurses' inadequacy in this area. ${ }^{4,10,31}$

Nurses' low knowledge of research methods, the weakness of nurses' education in clinical inquiry, poor access of nurses to research facilities, and lack of inservice training related to research have been cited as the major barriers to clinical inquiry in nursing. . $^{31,33,34}$

However, nurses have less confidence in research findings, ${ }^{35}$ time constraints, and lack of ability to apply research findings to clinical practice. .,10,35,36 $^{-1}$

In this study, the overall score of the nursing selfconcept measure was about $61 \%$. Nurses scored higher in the subscale of self-confidence and lower in the subscale of staff relations. In line with this finding, Golestan (2015) shows nurses' score is $68 \%$ in the nursing self-concept measure. ${ }^{23}$ A strong professional self-concept is especially important in critical care nurses due to their unstable and stressful work setting. ${ }^{37}$ However, studies have reported that Iranian nurses suffer from poor professional self-concept. ${ }^{14,38}$ This problem is attributed to reasons such as lack of knowledge, skills, management system, financial resources, and social image of the profession. ${ }^{31,39}$ The present study demonstrates increasing professional self-concept improves the quality of nurses' clinical performance. In this regard, a study shows that the positive self-concept is an endless source of energy for nurses to perform their duties and achieve their goals. This feature is especially important in stressful environments such as ICU, where there are patients with life-threatening conditions. ${ }^{23}$ A strong and positive professional self-concept enhances the specialized knowledge and clinical skills of nurses, which, in turn, helps them improve their quality of care. ${ }^{21}$

The professional concept of nursing is formed as a result of the relationship between biological and environmental factors and education; so it can be concluded that the professional concept of nursing grows due to the interaction between human and environmental factors. Learning and training play an important role in the development of self-concept. Therefore, this issue needs special attention from education officials and policy makers in the nursing profession to the current situation. Due to the low score of nurses' clinical research in this study, it is suggested that nurses become more familiar with research during their academic studies, they have sufficient research facilities (computer, internet, etc.) in the workplace, and their research should be supported and encouraged by hospital officials and nursing organizations.

\section{Conclusions}

On the findings of this study, professional self-concept and related domains including leadership, communication, staff relations, knowledge, caring, and self-confidence are significantly related to clinical performance and its domains include clinical judgment, advocacy, and moral agency, caring practices, collaboration, systems thinking, response to diversity, clinical inquiry, and facilitation of learning. In conclusion, the improvement of professional self-concept and its domains will improve nursing clinical performance in different domains. Therefore, strategies that strengthen professional selfconcept are recommended to improve nursing clinical performance.

\section{Limitations}

Since this was a cross-sectional study with a very limited number of participants, further studies on bigger populations are required to generalize these results.

\section{Acknowledgments}

The authors of this article thank all the nurses who participated in this study and also the Vice Chancellor for Research of Qom University of Medical Sciences.

\section{Ethical approval}

Ethical issues are not involved in this paper.

\section{Conflicts of interest}

All contributing authors declare no conflicts of interest.

\section{References}

1. Duffy JR. Quality Caring in Nursing and Health Professions: implications for Clinicians, Educators, and Leaders. New York, Springer Publishing Company; 2018.

2. Hibbert D, Aboshaiqah $A E$, Sienko $K A$, et al. Advancing nursing practice: The emergence of the role of advanced practice nurse in Saudi Arabia. Ann Saudi Med. 2017;37:72-78.

3. Rantz MJ, Flesner MK, Franklin J, et al. Better care, better quality: reducing avoidable hospitalizations of nursing home residents. J Nurs Care Q. 2015;30:290-297. 
4. Karimyar Jahromi M. Nurses' quality of performance in intensive care units based on Synergy Model. Iran J Nurs. 2013;26:74-83.

5. Sarafis P, Rousaki E, Tsounis A, et al. The impact of occupational stress on nurses' caring behaviors and their health related quality of life. BMC Nurs. 2016;15:56-65.

6. Kahya E, Oral N. Measurement of clinical nurse performance: Developing a tool including contextual items. J Nurs Educ Pract. 2018;8:112-123.

7. Cheraghi MA, Nasabadi N, Reza A, et al. Medication errors among nurses in intensive care units (ICU). $J$ Mazandaran Univ Med Sci. 2012;21:115-119.

8. Munroe B, Curtis K, Buckley T, Lewis M, Atkins L. Optimising implementation of a patient - assessment framework for emergency nurses: a mixed method study. J Clin Nurs. 2018;27:e269-e286.

9. Lee J-R, Kim E-M, Kim S-A, Oh EG. A systematic review of early warning systems' effects on nurses' clinical performance and adverse events among deteriorating ward patients. J Patient Saf. 2020;16:e104-e113.

10. Khoeiniha F, Sheikhi M, Shokati A, Mohammad Pour A. Nurses' clinical performance assessment in critical care units in teaching and non-teaching hospitals in Qazvin city: based on synergy model. $J$ Health Promot Manage. 2016;5:28-36.

11. Avia I, Hariyati RTS. Impact of hospital accreditation on quality of care: a literature review. Enferm Clin. 2019;29:315-320.

12. Musarezaie A, Irajpoor A, Abdoli S, Ahmadi M, Momeni-GhaleGhasemi T. How do we decline the medicinal errors and refusal in reporting medication errors in nurses in critical coronary unit? An actionresearch study. J Health Syst Res. 2013;9:594-604.

13. Nasiri E, Babatabar Darzi H, Mahmoodi Y. Nurses' drug calculation ability in intensive care unit (ICU). Iran J Crit Care Nurs. 2009;2:113-115.

14. Badiyepeymaie Jahromi Z, Kargar M, Ramezanli S. Study of the relationship between nurse selfconcept and clinical performance among nursing students. Jentashapir J Health Res. 2015;6:54-58.

15. Badiyepeymaye Jahromi Z, Keshavarzi S, Jahanbin I. Determination of the reliability and validity of the Persian version of nurses' self-concept questionnaire (NSCQ). J Nurs Educ. 2014;2: 63-71.

16. Sabanciogullari S, Dogan S. Professional self-concept in nurses and related factors: a sample from Turkey. Int J Caring Sci. 2017;10:1676-1684.

17. Cowin LS, Johnson M, Craven RG, Marsh HW. Causal modeling of self-concept, job satisfaction, and retention of nurses. Int J Nurs Stud. 2008;45:1449-1459.
18. Cowin LS, Hengstberger-Sims C. New graduate nurse self-concept and retention: a longitudinal survey. Int J Nurs Stud. 2006;43:59-70.

19. Lee HK, Yang HJ. Influence of professional selfconcept and professional autonomy on nursing performance of clinic nurses. Int J Bio-Sci Bio-Technol. 2015;7:297-310.

20. Montazeralfaraj R, Ahmadi E, Tafti AD, Barati $\mathrm{O}$, Bahrami MA. Measuring the nurses' professional self-concept and its correlation with working stress in Iranian educational Hospitals. Education. 2018;7:521-525.

21. Mosayebi M, Rassouli M, Nasiri M. Correlation of occupational stress with professional self-concept in pediatric nurses. J Health Promot Manage. 2018;6:23-29.

22. Stone PC, Low JT. Palliative medicine 0000.

23. Golestan F, Ashktorab T, Zohari Anboohi S, Mohtashami J, Salmani F. Professional self-concept in nurses working in intensive cares unit in hospitals affiliated to medical sciences universities of Tehran in 2014. Adv Nurs Midwifery. 2016;25:39-46.

24. Abbasinia M, Ahmadi F, Kazemnejad A. Patient advocacy in nursing: a concept analysis. Nurs Ethics. 2020;27:141-151.

25. Cowin L. Measuring nurses' self-concept. West $J$ Nurs Res. 2001;23:313-325.

26. Standing M. Clinical judgement and decision making in nursing. London: Learning Matters; 2017.

27. Gorski S, Piotrowicz K, Rewiuk K, et al. Nonpharmacological interventions targeted at delirium risk factors, delivered by trained volunteers (medical and psychology students), reduced need for antipsychotic medications and the length of hospital stay in aged patients admitted to an acute internal medicine ward: pilot study. BioMed Res Int. 2017;2017:1297164.

28. Greaves J, Goodall D, Berry A, Shrestha S, Richardson A, Pearson P. Nursing workloads and activity in critical care: A review of the evidence. Intensive Crit Care Nurs. 2018;48:10-20.

29. Sadeghi-Moghadam P, Ahangari R, Kamelian Z, Aghaali M. Comparison of neonatal outcome with meconium-stained amniotic fluid in normal vaginal delivery and cesarean section. Qom Univ Med Sci J. 2019;13:1-7.

30. Seidi J, Alhani F, Salsali M. Exploration of structure of clinical judgment of nurses: a grounded theory study. J Qual Res Health Sci. 2014;2:297-309.

31. Adib-Hajbaghery M. Evidence-based practice: Iranian nurses' perceptions. Worldviews Evid Based Nurs. 2009;6:93-101.

32. Mick J. Call to action how to implement evidencebased nursing practice. Nursing. 2017;47:36-43. 
33. Shifaza F, Evans D, Bradley H. Nurses' perceptions of barriers and facilitators to implement EBP in the Maldives. Adv Nurs. 2014;2014:698604.

34. Mokhtari R, AdibHajbaghery M, Yazdani-Darki M. Barriers to student research from the perspectives of nursing, health, and medical sciences students: a crosssectional study. Nurs Midwifery Stud. 2019;8:97-102.

35. Latifi S, Khalilpour A, Rabiee OL, Amani N. Barriers to research utilization among clinical nurses. $J$ Mazandaran Univ Med Sci. 2012;22:88-95.

36. Bahadori M, Raadabadi M, Ravangard R, Mahaki B. The barriers to the application of the research findings from the nurses' perspective: a case study in a teaching hospital. J Educ Health Promot. 2016;5:1-8.

37. Inoue KC, Gomes da Silva Versa GL, Misue Matsuda L. Stress level among intensive care nurses in the municipality of Paraná (Brazil). Invest Educ Enferm. 2014;32:69-77.

38. Jahanbin I, Badiyepeyma Z, Sharif F, Ghodsbin F, Keshavarzi $S$. The impact of teaching professional self-concept on clinical performance perception in nursing students. Life Sci J. 2012;9:653-659.

39. Hagbaghery MA, Salsali M, Ahmadi F. The factors facilitating and inhibiting effective clinical decisionmaking in nursing: a qualitative study. BMC Nurs. 2004;3:1-11.

40. Çöplü M, Tekinsoy Kartın P. Professional selfconcept and professional values of senior students of the nursing department. Nurs Ethics. 2019;26:1387-1397.

41. Hurley S, Edwards J, Cupp J, Phillips M. Nurses' perceptions of self as role models of health. West $J$ Nurs Res. 2018;40:1131-1147.

42. Havaei F, Mcphee M, Dahinten VS. The effect of nursing care delivery models on quality and safety outcomes of care: a cross sectional survey study of medical-surgical nurses. J Adv Nurs. 2019;75:2144-2155.

43. Han SJ, Koo HY. Influence of professional selfconcept, job overload and perceived organizational support on job involvement in clinical nurses. J Korean Acad Soc Nurs Educ. 2018;24:89-99. 